\title{
Estimation of Population Mean Using Known Median and Co-Efficent of Skewness
}

\author{
J. Subramani*, G. Kumarapandiyan \\ Department of Statistics, Pondicherry University, R V Nagar, Kalapet Puducherry, 605014, India
}

\begin{abstract}
The present paper deals with two modified ratio estimators for estimation of population mean of the study variable using the linear co mbination of the known population values of the Median and the Co-efficient of Skewness of the auxiliary variable. The biases and the mean squared errors of the proposed estimators are derived and are compared with that of existing modified ratio estimators for certain natural populations. Further we have also derived the conditions for which the proposed estimators perform better than the existing modified ratio estimators. From the empirical study it is also observed that the proposed modified ratio estimators perform better than the existing modified ratio estimators.
\end{abstract}

Keywords Bias, Mean Squared Error, Modified Ratio Estimators, Simple Random Sampling

\section{Introduction}

The sampling theory describes a wide variety of techniques for using auxiliary information to obtain more efficient estimators like Ratio, Product and Regression estimators for the estimation of the mean of the study variable Y. Ratio estimators, improves the precision of estimate of the population mean of a study variable by using prior information on auxiliary variable $\mathrm{X}$ which is positively correlated with the study variable Y. Over the years the ratio method of estimation has been extensively used because of its intuitive appeal and the computational simplicity. When the population parameters of the auxiliary variable $\mathrm{X}$ such as Population Mean, Co-efficient of Variation, Co-efficient of Kurtosis, Co-efficient of Skewness, Median are known, a number of modified estimators such as modified ratio estimators, modified product estimators and modified linear regression estimators are proposed in the literature. Before discussing further about the modified ratio estimators and the proposed modified ratio estimators the notations to be used in this paper are described below:

- $\mathrm{N}$ - Population size

- $\mathrm{n}$ - Sample size

- $\mathrm{f}=\mathrm{n} / \mathrm{N}$, Sampling fraction

- Y-Study variable

- $\mathrm{X}$ - Auxiliary variable

- $\bar{X}, \bar{Y}-$ Population means

- $\overline{\mathrm{x}}, \overline{\mathrm{y}}$ - Sample means

- $\mathrm{S}_{\mathrm{X}}, \mathrm{S}_{\mathrm{y}}-$ Population standard deviations

* Corresponding author:

drjsubramani@yahoo.co.in (J. Subramani)

Published online at http://journal.sapub.org/ajms

Copyright (C) 2012 Scientific \& Academic Publishing. All Rights Reserved
- $\mathrm{C}_{\mathrm{X}}, \mathrm{C}_{\mathrm{y}}-$ Co-efficient of variations

- $\rho$ - Co-efficient of correlation

- $\beta_{1}=\frac{\mathrm{N} \sum_{\mathrm{i}=1}^{\mathrm{N}}\left(\mathrm{X}_{\mathrm{i}}-\overline{\mathrm{X}}\right)^{3}}{(\mathrm{~N}-1)(\mathrm{N}-2) \mathrm{S}^{3}}$, Co-efficient of skewness of the auxiliary variable

- $\beta_{2}=\frac{\mathrm{N}(\mathrm{N}+1) \sum_{\mathrm{i}=1}^{\mathrm{N}}\left(\mathrm{X}_{\mathrm{i}}-\overline{\mathrm{X}}\right)^{4}}{(\mathrm{~N}-1)(\mathrm{N}-2)(\mathrm{N}-3) \mathrm{S}^{4}}-\frac{3(\mathrm{~N}-1)^{2}}{(\mathrm{~N}-2)(\mathrm{N}-3)}$, Co-efficient of kurtosis of the auxiliary variable

- $\mathrm{M}_{\mathrm{d}}$-Median of the auxiliary variable

- $\mathrm{B}($. $)$ - Bias of the estimator

- $\operatorname{MSE}($.) - Mean squared error of the estimator

- $\widehat{\mathrm{Y}}_{\mathrm{i}}\left(\widehat{\mathrm{Y}}_{\mathrm{pi}}\right)-$ Existing (proposed) modified ratio estimator of $\overline{\mathrm{Y}}$

The Ratio estimator for estimating the population mean $\overline{\mathrm{Y}}$ of the study variable $\mathrm{Y}$ is defined as

$$
\begin{gathered}
\widehat{\mathrm{Y}}_{\mathrm{R}}=\frac{\overline{\mathrm{y}}}{\overline{\mathrm{X}}} \overline{\mathrm{X}}=\widehat{\mathrm{R}} \overline{\mathrm{X}} \text { where } \widehat{\mathrm{R}}=\frac{\overline{\mathrm{y}}}{\overline{\mathrm{X}}}=\frac{\mathrm{y}}{\mathrm{X}} \\
\text { is the estimate of } \mathrm{R}=\frac{\overline{\mathrm{Y}}}{\overline{\mathrm{X}}}=\frac{\mathrm{Y}}{\mathrm{X}}
\end{gathered}
$$

The lists of modified ratio estimators together with their biases, mean squared errors and constants available in the literature are classified into two classes namely Class 1, Class 2 and are given respectively in Table 1 and Table 2 in the Appendix.

It is to be noted that "the existing modified ratio estimators" means the list of modified ratio estimators to be considered in this paper unless otherwise stated. It does not mean to the entire list of modified ratio estimators available in the literature. For a more detailed discussion on the ratio estimator and its modifications one may refer to Cochran[1], Kadilar and Cingi[2, 3], Koyuncu and Kadilar[4], Murthy[5], Prasad[6], Rao[7], Singh[9], Singh and Tailor[10,12], Singh et.al[11], Sisodia and Dwivedi[13], Subramani and Kumarapandiyan[14,15], Upadhyaya and Singh[16], Yan and Tian[17] and the references cited there in. 
The modified ratio estimators given in Table 1 and Table 2 are biased but have minimum mean squared errors compared to the classical ratio estimator. The list of estimators given in Table 1 and Table 2 uses the known values of the parameters like $\bar{X}, C_{x}, \beta_{1}, \beta_{2}, \rho, M_{d}$ and their linear combinations. Recently Yan and Tian[17] have used Coefficient of Skewness for the estimation of population meanHowever, it seems, no attempt is made to use the linear combination of known values of the Median and Co-efficient of Skewness of the auxiliary variable to improve the ratio estimator. The points discussed above have motivated us to introduce two modified ratio estimators using the linear co mb ination of the known values of Median and Co-efficient of Skewness of the auxiliary variable. When the population median and coefficient of skewness are unknown the proposed estimators can be modified using their respective estimates i.e sample median, and sample coefficient of skewness obtained from the sample. The proposed estimators can be applicable in the following practical situation.

1. A national park is partitioned into $\mathrm{N}$ units.

- $\mathrm{Y}=$ the number of animals in the $\mathrm{i}^{\text {th }}$ unit

- $\mathrm{X}=$ the size of the $\mathrm{i}^{\text {th }}$ unit

2. A certain city has $\mathrm{N}$ bookstores.

- $\mathrm{Y}=$ the sales of a given book title at the $\mathrm{i}^{\text {th }}$ bookstore

- $\mathrm{X}=$ the size of the $\mathrm{i}^{\text {th }}$ bookstore

3. A forest that has $\mathrm{N}$ trees.

- $\mathrm{Y}=$ the volume of the tree

- $\mathrm{X}=$ the diameter of the tree

\section{Proposed Modified Ratio Estimators}

In this section, we have suggested two modified ratio estimators using the linear combination of Median and Co-efficient of Skewness of the auxiliary variable. The proposed modified ratio estimators for estimating the population mean $\bar{Y}$ together with the first degree of approximation, the biases and mean squared errors and the constants are given below:

$$
\begin{aligned}
& \widehat{\mathrm{Y}}_{\mathrm{p} 1}=\overline{\mathrm{y}}\left[\frac{\overline{\mathrm{X}} \beta_{1}+\mathrm{M}_{\mathrm{d}}}{\overline{\mathrm{x}} \beta_{1}+\mathrm{M}_{\mathrm{d}}}\right] \\
& B\left(\widehat{\mathrm{Y}}_{\mathrm{p} 1}\right)=\frac{(1-\mathrm{f})}{\mathrm{n}} \overline{\mathrm{Y}}\left(\theta_{\mathrm{p} 1}^{2} \mathrm{C}_{\mathrm{x}}^{2}-\theta_{\mathrm{p} 1} \mathrm{C}_{\mathrm{x}} \mathrm{C}_{\mathrm{y}} \rho\right) \\
& \operatorname{MSE}\left(\widehat{\mathrm{Y}}_{\mathrm{p} 1}\right)=\frac{(1-\mathrm{f})}{\mathrm{n}} \overline{\mathrm{Y}}^{2}\left(\mathrm{C}_{\mathrm{y}}^{2}+\theta_{\mathrm{p} 1}^{2} \mathrm{C}_{\mathrm{x}}^{2}-2 \theta_{\mathrm{p} 1} \mathrm{C}_{\mathrm{x}} \mathrm{C}_{\mathrm{y}} \rho\right) \\
& \text { where } \theta_{\mathrm{p} 1}=\frac{\overline{\mathrm{x}} \beta_{1}}{\overline{\mathrm{X}} \beta_{1}+\mathrm{M}_{\mathrm{d}}} \\
& \widehat{\mathrm{Y}}_{\mathrm{p} 2}=\frac{\overline{\mathrm{y}}+\mathrm{b}(\overline{\mathrm{X}}-\overline{\mathrm{x}})}{\left(\overline{\mathrm{x}} \beta_{1}+\mathrm{M}_{\mathrm{d}}\right)}\left(\overline{\mathrm{X}} \beta_{1}+\mathrm{M}_{\mathrm{d}}\right) \\
& \mathrm{B}\left(\widehat{\mathrm{Y}}_{\mathrm{p} 2}\right)=\frac{(1-\mathrm{f})}{\mathrm{n}} \frac{\mathrm{S}_{\mathrm{x}}^{2}}{\overline{\mathrm{Y}}} R_{\mathrm{p} 2}^{2} \\
& \operatorname{MSE}\left(\widehat{\mathrm{Y}}_{\mathrm{p} 2}\right)=\frac{(1-\mathrm{f})}{\mathrm{n}}\left(\mathrm{R}_{\mathrm{p} 2}^{2} \mathrm{~S}_{\mathrm{x}}^{2}+\mathrm{S}_{\mathrm{y}}^{2}\left(1-\rho^{2}\right)\right) \\
& \text { where } R_{p 2}=\frac{\bar{Y} \beta_{1}}{\bar{X} \beta_{1}+M_{d}}
\end{aligned}
$$

\section{Efficiency Comparison}

For want of space; for the sake of convenience to the readers and for the ease of comparisons, the modified ratio estimators given in Table 1 , Table 2 are represented into two classes as given below. Further it is to be noted that the proposed estimator $\widehat{\mathrm{Y}}_{\mathrm{p} 1}$ is compared with the modified ratio estimators listed in Class 1 whereas the proposed estimator $\widehat{\mathrm{Y}}_{\mathrm{p} 2}$ is compared with the modified ratio estimators listed in Class 2.

Class 1:The biases, the mean squared errors and the constants of the modified ratio type estimators $\widehat{\mathrm{Y}}_{1}$ to $\widehat{\mathrm{Y}}_{9}$ listed in the Table 1 are represented in a single class (say, Class 1), which will be very much useful for comparing with that of proposed modified ratio estimators and are given below:

$$
\begin{gathered}
\operatorname{MSE}\left(\widehat{\mathrm{Y}}_{\mathrm{i}}\right)=\frac{(1-\mathrm{f})}{\mathrm{n}} \overline{\mathrm{Y}}_{\mathrm{i}}^{2}\left(\mathrm{C}_{\mathrm{y}}^{2}+\theta_{i}^{2} C_{\mathrm{x}}^{2}-2 \theta_{\mathrm{i}} C_{\mathrm{x}} C_{\mathrm{y}} \rho\right) ; \\
i=1,2,3, \ldots, 9
\end{gathered}
$$

where

$$
\begin{gathered}
\theta_{1}=\frac{\bar{X}}{\bar{X}+C_{x}}, \theta_{2}=\frac{\bar{X}}{\bar{X}+\beta_{2}}, \\
\theta_{3}=\frac{\bar{X}}{\bar{X}+\beta_{1}}, \theta_{4}=\frac{\bar{X}}{\bar{X}+\rho}, \\
\theta_{5}=\frac{\bar{X} C_{x}}{\bar{X} C_{x}+\beta_{2}}, \theta_{6}=\frac{\bar{X} \beta_{2}}{\bar{X} \beta_{2}+C_{x}}, \\
\theta_{7}=\frac{\bar{x} \beta_{1}}{\bar{x} \beta_{1}+\beta_{2}}, \theta_{8}=\frac{\bar{x} C_{x}}{\bar{x} C_{x}+\beta_{1}} \text { and } \theta_{9}=\frac{\bar{X}}{\bar{X}+M_{d}}
\end{gathered}
$$

Class 2:The biases, the mean squared errors and the constants of the 11 modified ratio estimators $\widehat{\mathrm{Y}}_{1}$ to $\widehat{\mathrm{Y}}_{11}$ listed in the Table 2 are represented in a single class (say, Class 2), which will be very much useful for comparing with that of proposed modified ratio estimators and are given below:

$$
\begin{aligned}
& B\left(\widehat{\bar{Y}}_{\mathrm{j}}\right)=\frac{(1-\mathrm{f})}{\mathrm{n}} \frac{S_{\mathrm{x}}^{2}}{\overline{\mathrm{Y}}} R_{\mathrm{j}}^{2} \\
& \operatorname{MSE}\left(\widehat{\mathrm{Y}}_{\mathrm{j}}\right)=\frac{(1-\mathrm{f})}{\mathrm{n}}\left(\mathrm{R}_{\mathrm{j}}^{2} S_{\mathrm{x}}^{2}+S_{\mathrm{y}}^{2}\left(1-\rho^{2}\right)\right) ; j=1,2,3, \ldots, 11 \\
& \text { where } R_{1}=\frac{\bar{Y}}{\bar{X}}, R_{2}=\frac{\bar{Y}}{\bar{X}+C_{\mathrm{X}}} \text {, } \\
& \mathrm{R}_{3}=\frac{\overline{\mathrm{Y}}}{\overline{\mathrm{X}}+\beta_{2}}, \mathrm{R}_{4}=\frac{\overline{\mathrm{Y}} \beta_{2}}{\overline{\mathrm{X}} \beta_{2}+\mathrm{C}_{\mathrm{x}}}, \\
& R_{5}=\frac{\overline{\mathrm{Y}} \mathrm{C}_{\mathrm{X}}}{\overline{\mathrm{X}} \mathrm{C}_{\mathrm{X}}+\beta_{2}}, \mathrm{R}_{6}=\frac{\overline{\mathrm{Y}}}{\overline{\mathrm{X}}+\beta_{1}}, \mathrm{R}_{7}=\frac{\overline{\mathrm{Y}}}{\overline{\mathrm{X}}+\rho}, \mathrm{R}_{8}=\frac{\overline{\mathrm{Y}} \mathrm{C}_{\mathrm{X}}}{\overline{\mathrm{X}} \mathrm{C}_{\mathrm{X}}+\rho}, \\
& \mathrm{R}_{9}=\frac{\overline{\mathrm{Y}} \rho}{\overline{\mathrm{X}}_{\rho}+\mathrm{C}_{\mathrm{x}}}, \mathrm{R}_{10}=\frac{\overline{\mathrm{Y}} \beta_{2}}{\overline{\mathrm{X}}_{2}+\rho} \text { and } \mathrm{R}_{11}=\frac{\overline{\mathrm{Y}} \rho}{\overline{\mathrm{X}}_{\rho}+\beta_{2}}
\end{aligned}
$$

As derived earlier in section 2 , the biases, the mean squared errors and the constants of two proposed modified ratio estimators are given below:

$$
\begin{gathered}
\mathrm{B}\left(\widehat{\mathrm{Y}}_{\mathrm{p} 1}\right)=\frac{(1-\mathrm{f})}{\mathrm{n}} \overline{\mathrm{Y}}\left(\theta_{\mathrm{p} 1}^{2} \mathrm{C}_{\mathrm{x}}^{2}-\theta_{\mathrm{p} 1} \mathrm{C}_{\mathrm{x}} \mathrm{C}_{\mathrm{y}} \rho\right) \\
\operatorname{MSE}\left(\widehat{\mathrm{Y}}_{\mathrm{p} 1}\right)=\frac{(1-\mathrm{f})}{\mathrm{n}} \overline{\mathrm{Y}}^{2}\left(\mathrm{C}_{\mathrm{y}}^{2}+\theta_{\mathrm{p} 1}^{2} \mathrm{C}_{\mathrm{x}}^{2}-2 \theta_{\mathrm{p} 1} \mathrm{C}_{\mathrm{x}} \mathrm{C}_{\mathrm{y}} \rho\right) \\
\text { where } \theta_{\mathrm{p} 1}=\frac{\overline{\mathrm{X}}_{\beta_{1}}}{\overline{\mathrm{X}} \beta_{1}+\mathrm{M}_{\mathrm{d}}} \\
\mathrm{B}\left(\widehat{\mathrm{Y}}_{\mathrm{p} 2}\right)=\frac{(1-\mathrm{f})}{\mathrm{n}} \frac{S_{\mathrm{x}}^{2}}{\overline{\mathrm{Y}}} R_{\mathrm{p} 2}^{2}
\end{gathered}
$$




$$
\begin{gathered}
\operatorname{MSE}\left(\widehat{\mathrm{Y}}_{\mathrm{p} 2}\right)=\frac{(1-\mathrm{f})}{\mathrm{n}}\left(\mathrm{R}_{\mathrm{p} 2}^{2} S_{\mathrm{x}}^{2}+S_{\mathrm{y}}^{2}\left(1-\rho^{2}\right)\right) \\
\text { where } \mathrm{R}_{\mathrm{p} 2}=\frac{\overline{\mathrm{Y}} \beta_{1}}{\overline{\mathrm{X}} \beta_{1}+\mathrm{M}_{\mathrm{d}}}
\end{gathered}
$$

Fro $m$ the expressions given in (4) and (6) we have derived the conditions for which the proposed estimator $\widehat{\mathrm{Y}}_{\mathrm{p} 1}$ is more efficient than the existing modified ratio estimators given in Class $1, \widehat{\mathrm{Y}}_{\mathrm{i}} ; \mathrm{i}=1,2,3, \ldots, 9$ and are given below.

$$
\operatorname{MSE}\left(\widehat{\bar{Y}}_{\mathrm{p} 1}\right)<\operatorname{MSE}\left(\widehat{\bar{Y}}_{\mathrm{i}}\right) \text { if } \rho<\frac{\left(\theta_{\mathrm{p} 1}+\theta_{\mathrm{i}}\right)}{2} \frac{\mathrm{C}_{\mathrm{x}}}{\mathrm{C}_{\mathrm{y}}} ; \mathrm{i}=1,2,3, \ldots, 9
$$

Fro $m$ the expressions given in (5) and (7) we have derived the conditions for which the proposed estimator $\widehat{\bar{Y}}_{\mathrm{p} 2}$ is more efficient than the existing modified ratio estimators given in Class $2, \widehat{\mathrm{Y}}_{j} ; j=1,2,3, \ldots, 11$ and are given below:

$$
\operatorname{MSE}\left(\widehat{\mathrm{Y}}_{\mathrm{p} 2}\right)<\operatorname{MSE}\left(\widehat{\mathrm{Y}}_{\mathrm{j}}\right) \text { if } \mathrm{R}_{\mathrm{p} 2}<\mathrm{R}_{\mathrm{j}} ; \mathrm{j}=1,2,3, \ldots, 11
$$

\section{Numerical Study}

Table 3. Parameters and Constants of the Populations

\begin{tabular}{|c|c|c|}
\hline Parameters & Population 1 & Population 2 \\
\hline $\mathrm{N}$ & 34 & 80 \\
\hline $\mathrm{n}$ & 20 & 20 \\
\hline$\overline{\mathrm{Y}}$ & 856.4117 & 51.8264 \\
\hline$\overline{\mathrm{X}}$ & 208.8823 & 2.8513 \\
\hline$\rho$ & 0.4491 & 0.9150 \\
\hline $\mathrm{S}_{\mathrm{y}}$ & 733.1407 & 18.3569 \\
\hline $\mathrm{C}_{\mathrm{y}}$ & 0.8561 & 0.3542 \\
\hline $\mathrm{S}_{\mathrm{x}}$ & 150.5059 & 2.7042 \\
\hline $\mathrm{C}_{\mathrm{x}}$ & 0.7205 & 0.9484 \\
\hline$\beta_{2}$ & 0.0978 & 1.3005 \\
\hline$\beta_{1}$ & 0.9782 & 0.6978 \\
\hline $\mathrm{M}_{\mathrm{d}}$ & 150.0000 & 1.4800 \\
\hline
\end{tabular}

Table 4. The constants of the (Class 1) existing and proposed modified ratio est imators

\begin{tabular}{|l|c|c|}
\hline \multirow{2}{*}{ Estimator } & \multicolumn{2}{c|}{ Constants $\boldsymbol{\theta}_{\mathbf{i}}$} \\
\cline { 2 - 3 } & Population 1 & Population 2 \\
\hline$\widehat{\mathrm{Y}}_{1}$ Sisodia and Dwivedi[13] & 0.9966 & 0.7504 \\
\hline$\widehat{\mathrm{Y}}_{2}$ Singh et.al[11] & 0.9995 & 0.6868 \\
\hline$\widehat{\mathrm{Y}}_{3}$ Yan and Tian[17] & 0.9953 & 0.8034 \\
\hline$\widehat{\mathrm{Y}}_{4}$ Singh and Tailor[10] & 0.9979 & 0.7571 \\
\hline$\widehat{\mathrm{Y}}_{5}$ Upadhyaya and Singh[16] & 0.9994 & 0.6753 \\
\hline$\widehat{\mathrm{Y}}_{6}$ Upadhyaya and Singh[16] & 0.9658 & 0.7963 \\
\hline$\widehat{\mathrm{Y}}_{7}$ Yan and Tian[17] & 0.9542 & 0.8416 \\
\hline$\widehat{\mathrm{Y}}_{8}$ Yan and Tian[17] & 0.9935 & 0.7949 \\
\hline$\widehat{\overline{\mathrm{Y}}}_{9}$ Subramani and Kumarapandiyan[15] & 0.5820 & 0.6583 \\
\hline$\widehat{\mathrm{Y}}_{\mathrm{p} 1}$ (Proposed estimator)* & $0.5767^{*}$ & $0.5734^{*}$ \\
\hline
\end{tabular}

The performances of the proposed modified ratio estimators are assessed with that of existing modified ratio estimators listed in Table 1 and Table 2 for certain natural populations. In this connection, we have considered two natural populations for the assessment of the performances of the proposed modified ratio estimators with that of existing modified ratio estimators. The population 1 is taken from Singh and Chaudhary[8] given in page 177 and population 2 is taken from Murthy[5] given in page 228. The population parameters and the constants computed from the above populations are given below:

The constants of the existing and proposed modified ratio estimators for the above populations are given in the Table 4

\begin{tabular}{|c|c|c|}
\hline \multirow{2}{*}{ Estimator } & \multicolumn{2}{|c|}{ Constants $\mathbf{R}_{\mathbf{j}}$} \\
\hline & Population 1 & Population 2 \\
\hline$\widehat{\overline{\mathrm{Y}}}_{1}$ Kadilar and Cingi[2] & 4.1000 & 18.1764 \\
\hline$\widehat{\overline{\mathrm{Y}}}_{2}$ Kadilar and Cingi[2] & 4.0859 & 13.6396 \\
\hline 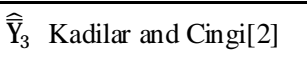 & 4.0981 & 12.4829 \\
\hline$\widehat{\overline{\mathrm{Y}}}_{4}$ Kadilar and Cingi[2] & 3.9598 & 14.4744 \\
\hline$\widehat{\overline{\mathrm{Y}}}_{5}$ Kadilar and Cingi[2] & 4.0973 & 12.2737 \\
\hline $\begin{array}{ll}\overline{\mathrm{Y}}_{6} & \text { Yan and Tian[17] } \\
\end{array}$ & 4.0809 & 14.6027 \\
\hline \begin{tabular}{|l|l}
$\hat{\bar{Y}}_{7}$ & Kadilar and Cingi[3]
\end{tabular} & 4.0912 & 13.7606 \\
\hline $\begin{array}{ll}\widehat{\overline{\mathrm{Y}}}_{8} & \text { Kadilar and Cingi[3] }\end{array}$ & 4.0878 & 13.5810 \\
\hline$\widehat{\overline{\mathrm{Y}}}_{9}$ Kadilar and Cingi[3] & 4.0687 & 13.3305 \\
\hline$\widehat{\overline{\mathrm{Y}}}_{10} \quad$ Kadilar and Cingi[3] & 4.0115 & 14.5790 \\
\hline$\widehat{\overline{\mathrm{Y}}}_{11} \quad$ Kadilar and Cingi[3] & 4.0957 & 12.1299 \\
\hline$\widehat{\overline{\mathrm{Y}}}_{\mathrm{p} 2}$ (Proposed estimator)* & $2.3643^{*}$ & $10.4231^{*}$ \\
\hline
\end{tabular}
and Table 5:

Table 5. The constants of the (Class 2) existing and proposed modified ratio est imators

The biases of the existing and proposed modified ratio estimators for the above populations are given in the Table 6 and Table 7:

Table 6. The biases of the (Class 1 ) existing and proposed modified ratio estimators

\begin{tabular}{|l|c|c|}
\hline \multirow{2}{*}{ Estimator } & \multicolumn{2}{c|}{ Bias B(.) } \\
\cline { 2 - 3 } & Population 1 & Population 2 \\
\hline$\widehat{\mathrm{Y}}_{1}$ Sisodia and Dwivedi[13] & 4.2233 & 0.5361 \\
\hline$\widehat{\widehat{\mathrm{Y}}}_{\text {S Singh et.al[11] }}$ & 4.2631 & 0.4142 \\
\hline$\widehat{\mathrm{Y}}_{3}$ Yan and Tian[17] & 4.2070 & 0.6484 \\
\hline$\widehat{\mathrm{Y}}_{4}$ Singh and Tailor[10] & 4.2406 & 0.5497 \\
\hline$\widehat{\mathrm{Y}}_{5}$ Upadhyaya and Singh[16] & 4.2607 & 0.3937 \\
\hline$\widehat{\mathrm{Y}}_{6}$ Upadhyaya and Singh[16] & 3.8212 & 0.6328 \\
\hline$\widehat{\mathrm{Y}}_{7}$ Yan and Tian[17] & 3.6732 & 0.7355 \\
\hline$\widehat{\mathrm{Y}}_{8}$ Yan and Tian[17] & 4.1831 & 0.6297 \\
\hline$\widehat{\mathrm{Y}}_{9}$ Subramani and Kumarapandiyan[15] & 0.2581 & 0.3643 \\
\hline$\widehat{\mathrm{Y}}_{\text {p1 }}$ (Proposed estimator)* & $0.2273^{*}$ & $0.2323^{*}$ \\
\hline
\end{tabular}


Table 7. The biases of the (Class 2) existing and proposed modified ratio estimators

\begin{tabular}{|c|c|c|}
\hline \multirow{2}{*}{ Estimator } & \multicolumn{2}{|c|}{$\operatorname{Bias} \mathbf{B}()}$. \\
\hline & Population 1 & Population 2 \\
\hline$\widehat{\overline{\mathrm{Y}}}_{1}$ Kadilar and Cingi[2] & 9.1539 & 1.7481 \\
\hline$\widehat{\overline{\mathrm{Y}}}_{2}$ Kadilar and Cingi[2] & 9.0911 & 0.9844 \\
\hline$\widehat{\widehat{\mathrm{Y}}}_{3} \quad$ Kadilar and Cingi[2] & 9.1454 & 0.8245 \\
\hline$\widehat{\widehat{\mathrm{Y}}}_{4}$ Kadilar and Cingi[2] & 8.5387 & 1.1086 \\
\hline$\widehat{\overline{\mathrm{Y}}}_{5}$ Kadilar and Cingi[2] & 9.1420 & 0.7971 \\
\hline$\widehat{\overline{\mathrm{Y}}}_{6}$ Yan and Tian[17] & 9.0688 & 1.1283 \\
\hline $\begin{array}{ll}\widehat{\overline{\mathrm{Y}}}_{7} & \text { Kadilar and Cingi[3] }\end{array}$ & 9.1147 & 1.0019 \\
\hline $\begin{array}{ll}\hat{\mathrm{Y}}_{8} & \text { Kadilar and Cingi[3] }\end{array}$ & 9.0995 & 0.9759 \\
\hline$\widehat{\overline{\mathrm{Y}}}_{9} \quad$ Kadilar and Cingi[3] & 9.0149 & 0.9403 \\
\hline$\widehat{\overline{\mathrm{Y}}}_{10}$ Kadilar and Cingi[3] & 8.7630 & 1.1246 \\
\hline$\widehat{\overline{\mathrm{Y}}}_{11}$ Kadilar and Cingi[3] & 9.1349 & 0.7785 \\
\hline$\widehat{\overline{\mathrm{Y}}}_{\mathrm{p} 2}$ (Proposed estimator)* & $5.2731^{*}$ & $0.6691^{*}$ \\
\hline
\end{tabular}

The mean squared errors of the existing and proposed modified ratio estimators for the above populations are given in the Table 8 and Table 9:

Table 8. The mean squared errors of the (Class 1) existing and proposed modified ratio estimators

\begin{tabular}{|c|c|c|}
\hline \multirow{2}{*}{ Estimator } & \multicolumn{2}{|c|}{ Mean Squared Error MSE(.) } \\
\hline & Population 1 & Population 2 \\
\hline$\widehat{\overline{\mathrm{Y}}}_{1}$ Sisodia and Dwivedi[13] & 10514.2250 & 17.1881 \\
\hline$\widehat{\overline{\mathrm{Y}}}_{2}$ Singh et.al[11] & 10535.8620 & 12.8426 \\
\hline$\widehat{\widehat{Y}}_{3}$ Yan and Tian[17] & 10505.3563 & 21.3660 \\
\hline$\widehat{\widehat{Y}}_{4}$ Singh and Tailor[10] & 10523.6171 & 17.6849 \\
\hline$\widehat{\widehat{Y}}_{5}$ Upadhyaya and Singh[16] & 10534.5417 & 12.1351 \\
\hline$\widehat{\widehat{\mathrm{Y}}}_{6}$ Upadhyaya and Singh[16] & 10298.4432 & 20.7801 \\
\hline$\widehat{\overline{\mathrm{Y}}}_{7}$ Yan and Tian[17] & 10220.4736 & 24.6969 \\
\hline$\widehat{\mathrm{Y}}_{8}$ Yan and Tian[17] & 10492.3779 & 20.6613 \\
\hline $\begin{array}{l}\widehat{\overline{\mathrm{Y}}}_{9} \text { Subramani and } \\
\text { Kumarapandiyan[15] }\end{array}$ & 8852.3417 & 11.1366 \\
\hline$\widehat{\overline{\mathrm{Y}}}_{\mathrm{p} 1}$ (Proposed estimator)* & $8848.4821^{*}$ & $6.9213^{*}$ \\
\hline
\end{tabular}

From the values of Table 6 and Table 7, it is observed that the bias of the proposed modified ratio estimator $\widehat{\mathrm{Y}}_{\mathrm{p} 1}$ is less than the biases of the existing modified ratio estimators $\widehat{\mathrm{Y}}_{\mathrm{i}} ; \mathrm{i}=1,2,3, \ldots, 9$ given in Class 1 and the bias of the proposed modified ratio estimator $\widehat{\mathrm{Y}}_{\mathrm{p} 2}$ is less than the biases of the existing modified ratio estimators $\widehat{\hat{Y}}_{j} ; j=1,2,3, \ldots, 11$ given in Class 2. Similarly from the values of Table 8 and Table 9 , it is observed that the mean squared error of the proposed modified ratio estimator $\widehat{\mathrm{Y}}_{\mathrm{p} 1}$ is less than the mean squared errors of the existing modified ratio estimators $\widehat{\mathrm{Y}}_{\mathrm{i}} ; \mathrm{i}=1,2,3, \ldots, 9$ given in Class 1 and the mean squared error of the proposed modified ratio estimator $\widehat{\bar{Y}}_{\mathrm{p} 2}$ is less than the mean squared errors of the existing modified ratio estimators $\widehat{\mathrm{Y}}_{\mathrm{j}} ; \mathrm{j}=1,2,3, \ldots, 11$ given in Class 2.

Table 9. The mean squared errors of the (Class 2) existing and proposed modified ratio estimators

\begin{tabular}{|c|c|c|}
\hline \multirow{2}{*}{ Estimator } & \multicolumn{2}{|c|}{ Mean Squared Error MSE(.) } \\
\cline { 2 - 3 } & Population 1 & Population 2 \\
\hline$\widehat{\widehat{Y}}_{1}$ Kadilar and Cingi[2] & 16673.4489 & 92.6563 \\
\hline$\widehat{\mathrm{Y}}_{2}$ Kadilar and Cingi[2] & 16619.6435 & 53.0736 \\
\hline$\widehat{\mathrm{Y}}_{3}$ Kadilar and Cingi[2] & 16666.1389 & 44.7874 \\
\hline$\widehat{\overline{\mathrm{Y}}}_{4}$ Kadilar and Cingi[2] & 16146.6142 & 59.5095 \\
\hline$\widehat{\mathrm{Y}}_{5}$ Kadilar and Cingi[2] & 16663.3064 & 43.3674 \\
\hline$\widehat{\mathrm{Y}}_{6}$ Yan and Tian[17] & 16600.5393 & 60.5325 \\
\hline$\widehat{\mathrm{Y}}_{7}$ Kadilar and Cingi[3] & 16639.8457 & 53.9825 \\
\hline$\widehat{\overline{\mathrm{Y}}}_{8}$ Kadilar and Cingi[3] & 16626.8702 & 52.6365 \\
\hline$\widehat{\mathrm{Y}}_{9}$ Kadilar and Cingi[3] & 16554.4002 & 50.7876 \\
\hline$\widehat{\mathrm{Y}}_{10}$ Kadilar and Cingi[3] & 16338.6465 & 60.3426 \\
\hline$\widehat{\overline{\mathrm{Y}}}_{11}$ Kadilar and Cingi[3] & 16657.1867 & 42.4051 \\
\hline$\widehat{\overline{\mathrm{Y}}}_{\mathrm{p} 2}$ (Proposed estimat or)* & $11440.8220 *$ & $31.8493 *$ \\
\hline
\end{tabular}

\section{Conclusions}

In this paper we have proposed two modified ratio estimators using linear combination of Median and Co-efficient of Skewness of the auxiliary variable. The biases and mean squared errors of the proposed estimators are obtained and compared with that of existing modified ratio estimators. Further we have derived the conditions for which the proposed estimators are more efficient than the existing modified ratio estimators. We have also ass essed the performances of the proposed estimators for some known populations and observed that the biases and mean squared errors of the proposed estimators are less than the biases and mean squared errors of the existing modified ratio estimators. 
Hence we strongly recommend the proposed modified estimators over the existing modified ratio estimators for the use of practical applications.

\section{APPENDIX}

\section{ACKNOWLEDGEMENTS}

The authors are thankful to the referees for their constructive comments. The second author wishes to thank the Vice Chancellor, Pondicherry University and other University authorities for the financial assistance to carry out this research work through the University Fellowship.

Table 1. Existing modified ratio est imators (Class 1) with their biases, mean squared errors and their const ants

\begin{tabular}{|c|c|c|c|}
\hline Estimator & Bias - $\mathbf{B}()$. & Mean squared error $\mathbf{M S E}()$. & Constant $\boldsymbol{\theta}_{\mathbf{i}}$ \\
\hline $\begin{array}{l}\widehat{\bar{Y}}_{1}=\bar{y}\left[\frac{\bar{X}+C_{x}}{\bar{x}+C_{x}}\right] \\
\text { Sisodia and Dwivedi[13] }\end{array}$ & $\frac{(1-f)}{n} \bar{Y}\left(\theta_{1}^{2} C_{x}^{2}-\theta_{1} C_{x} C_{y} \rho\right)$ & $\frac{(1-f)}{n} \bar{Y}^{2}\left(C_{y}^{2}+\theta_{1}^{2} C_{x}^{2}-2 \theta_{1} C_{x} C_{y} \rho\right)$ & $\theta_{1}=\frac{\bar{X}}{\bar{X}+C_{x}}$ \\
\hline $\begin{array}{l}\widehat{\bar{Y}}_{2}=\bar{y}\left[\frac{\bar{X}+\beta_{2}}{\bar{x}+\beta_{2}}\right] \\
\text { Singh et.al[11] }\end{array}$ & $\frac{(1-f)}{n} \bar{Y}\left(\theta_{2}^{2} C_{x}^{2}-\theta_{2} C_{x} C_{y} \rho\right)$ & $\frac{(1-f)}{n} \bar{Y}^{2}\left(C_{y}^{2}+\theta_{2}^{2} C_{x}^{2}-2 \theta_{2} C_{x} C_{y} \rho\right)$ & $\theta_{2}=\frac{\bar{X}}{\bar{X}+\beta_{2}}$ \\
\hline $\begin{array}{l}\widehat{\mathrm{Y}}_{3}=\overline{\mathrm{y}}\left[\frac{\overline{\mathrm{X}}+\beta_{1}}{\overline{\mathrm{X}}+\beta_{1}}\right] \\
\text { Yan and Tian[15] }\end{array}$ & $\frac{(1-f)}{n} \bar{Y}\left(\theta_{3}^{2} C_{x}^{2}-\theta_{3} C_{x} C_{y} \rho\right)$ & $\frac{(1-f)}{n} \bar{Y}^{2}\left(C_{y}^{2}+\theta_{3}^{2} C_{x}^{2}-2 \theta_{3} C_{x} C_{y} \rho\right)$ & $\theta_{3}=\frac{\bar{X}}{\bar{X}+\beta_{1}}$ \\
\hline $\begin{array}{l}\widehat{\bar{Y}}_{4}=\bar{y}\left[\frac{\bar{X}+\rho}{\bar{x}+\rho}\right] \\
\text { Singh and Tailor }[10]\end{array}$ & $\frac{(1-f)}{n} \bar{Y}\left(\theta_{4}^{2} C_{x}^{2}-\theta_{4} C_{x} C_{y} \rho\right)$ & $\frac{(1-f)}{n} \bar{Y}^{2}\left(C_{y}^{2}+\theta_{4}^{2} C_{x}^{2}-2 \theta_{4} C_{x} C_{y} \rho\right)$ & $\theta_{4}=\frac{\bar{X}}{\bar{X}+\rho}$ \\
\hline $\begin{array}{l}\widehat{\mathrm{Y}}_{5}=\overline{\mathrm{y}}\left[\frac{\overline{\mathrm{X}} \mathrm{C}_{\mathrm{x}}+\beta_{2}}{\overline{\mathrm{x}} \mathrm{C}_{\mathrm{x}}+\beta_{2}}\right] \\
\text { Upadhyaya and Singh[16] }\end{array}$ & $\frac{(1-f)}{n} \bar{Y}\left(\theta_{5}^{2} C_{x}^{2}-\theta_{5} C_{x} C_{y} \rho\right)$ & $\frac{(1-f)}{n} \bar{Y}^{2}\left(C_{y}^{2}+\theta_{5}^{2} C_{x}^{2}-2 \theta_{5} C_{x} C_{y} \rho\right)$ & $\theta_{5}=\frac{\overline{\mathrm{X}} \mathrm{C}_{\mathrm{x}}}{\overline{\mathrm{X}} \mathrm{C}_{\mathrm{x}}+\beta_{2}}$ \\
\hline $\begin{array}{l}\widehat{\widehat{Y}}_{6}=\bar{y}\left[\frac{\bar{X} \beta_{2}+C_{x}}{\bar{x} \beta_{2}+C_{x}}\right] \\
\text { Upadhyaya and Singh[16] }\end{array}$ & $\frac{(1-f)}{n} \bar{Y}\left(\theta_{6}^{2} C_{x}^{2}-\theta_{6} C_{x} C_{y} \rho\right)$ & $\frac{(1-f)}{n} \bar{Y}^{2}\left(C_{y}^{2}+\theta_{6}^{2} C_{x}^{2}-2 \theta_{6} C_{x} C_{y} \rho\right)$ & $\theta_{6}=\frac{\overline{\mathrm{X}} \beta_{2}}{\overline{\mathrm{X}} \beta_{2}+\mathrm{C}_{\mathrm{x}}}$ \\
\hline $\begin{array}{l}\widehat{\bar{Y}}_{7}=\bar{y}\left[\frac{\bar{X} \beta_{1}+\beta_{2}}{\bar{x} \beta_{1}+\beta_{2}}\right] \\
\text { Yan and Tian[17] }\end{array}$ & $\frac{(1-f)}{n} \bar{Y}\left(\theta_{7}^{2} C_{x}^{2}-\theta_{8} C_{x} C_{y} \rho\right)$ & $\frac{(1-f)}{n} \bar{Y}^{2}\left(C_{y}^{2}+\theta_{7}^{2} C_{x}^{2}-2 \theta_{8} C_{x} C_{y} \rho\right)$ & $\theta_{7}=\frac{\bar{X} \beta_{1}}{\bar{X} \beta_{1}+\beta_{2}}$ \\
\hline $\begin{array}{l}\widehat{\bar{Y}}_{8}=\bar{y}\left[\frac{\bar{X} C_{x}+\beta_{1}}{\bar{x} C_{x}+\beta_{1}}\right] \\
\text { Yan and Tian[17] }\end{array}$ & $\frac{(1-f)}{n} \bar{Y}\left(\theta_{8}^{2} C_{x}^{2}-\theta_{8} C_{x} C_{y} \rho\right)$ & $\frac{(1-f)}{n} \bar{Y}^{2}\left(C_{y}^{2}+\theta_{8}^{2} C_{x}^{2}-2 \theta_{8} C_{x} C_{y} \rho\right)$ & $\theta_{8}=\frac{\overline{\mathrm{X}} \mathrm{C}_{\mathrm{x}}}{\overline{\mathrm{X}} \mathrm{C}_{\mathrm{x}}+\beta_{1}}$ \\
\hline $\begin{array}{l}\widehat{\overline{\mathrm{Y}}}_{9}=\overline{\mathrm{y}}\left[\frac{\overline{\mathrm{X}}+\mathrm{M}_{\mathrm{d}}}{\overline{\mathrm{X}}+\mathrm{M}_{\mathrm{d}}}\right] \\
\text { Subramani and } \\
\text { Kumarapandiyan[15] }\end{array}$ & $\frac{(1-f)}{n} \bar{Y}\left(\theta_{9}^{2} C_{x}^{2}-\theta_{9} C_{x} C_{y} \rho\right)$ & $\frac{(1-f)}{n} \bar{Y}^{2}\left(C_{y}^{2}+\theta_{9}^{2} C_{x}^{2}-2 \theta_{9} C_{x} C_{y} \rho\right)$ & $\theta_{9}=\frac{\bar{X}}{\bar{X}+M_{d}}$ \\
\hline
\end{tabular}


Table 2. Existing modified ratio est imators (Class 2) with their biases, mean squared errors and their const ants

\begin{tabular}{|c|c|c|c|}
\hline Estimator & $\operatorname{Bias-B}()$. & Mean squared error $\mathbf{M S E}()$. & Constant $\mathbf{R}_{\mathbf{i}}$ \\
\hline $\begin{array}{l}\widehat{\mathrm{Y}}_{1}=\frac{\overline{\mathrm{y}}+\mathrm{b}(\overline{\mathrm{X}}-\overline{\mathrm{x}})}{\overline{\mathrm{x}}} \overline{\mathrm{X}} \\
\text { Kadilar and Cingi }[2]\end{array}$ & $\frac{(1-f)}{n} \frac{S_{x}^{2}}{\bar{Y}} R_{1}^{2}$ & $\frac{(1-f)}{n}\left(R_{1}^{2} S_{x}^{2}+S_{y}^{2}\left(1-\rho^{2}\right)\right)$ & $\mathrm{R}_{1}=\frac{\overline{\mathrm{Y}}}{\overline{\mathrm{X}}}$ \\
\hline $\begin{array}{l}\widehat{\mathrm{Y}}_{2}=\frac{\overline{\mathrm{y}}+\mathrm{b}(\overline{\mathrm{X}}-\overline{\mathrm{x}})}{\left(\overline{\mathrm{x}}+\mathrm{C}_{\mathrm{x}}\right)}\left(\overline{\mathrm{X}}+\mathrm{C}_{\mathrm{x}}\right) \\
\text { Kadilar and Cingi[2] }\end{array}$ & $\frac{(1-f)}{n} \frac{S_{x}^{2}}{\bar{Y}} R_{2}^{2}$ & $\frac{(1-f)}{n}\left(R_{2}^{2} S_{x}^{2}+S_{y}^{2}\left(1-\rho^{2}\right)\right)$ & $\mathrm{R}_{2}=\frac{\overline{\mathrm{Y}}}{\overline{\mathrm{X}}+\mathrm{C}_{\mathrm{x}}}$ \\
\hline $\begin{array}{l}\widehat{\mathrm{Y}}_{3}=\frac{\overline{\mathrm{y}}+\mathrm{b}(\overline{\mathrm{X}}-\overline{\mathrm{x}})}{\left(\overline{\mathrm{x}}+\beta_{2}\right)}\left(\overline{\mathrm{X}}+\beta_{2}\right) \\
\text { Kadilar and Cingi[2] }\end{array}$ & $\frac{(1-f)}{n} \frac{S_{x}^{2}}{\bar{Y}} R_{3}^{2}$ & $\frac{(1-f)}{n}\left(R_{3}^{2} S_{x}^{2}+S_{y}^{2}\left(1-\rho^{2}\right)\right)$ & $R_{3}=\frac{\bar{Y}}{\bar{X}+\beta_{2}}$ \\
\hline $\begin{array}{l}\widehat{\mathrm{Y}}_{4}=\frac{\overline{\mathrm{y}}+\mathrm{b}(\overline{\mathrm{X}}-\overline{\mathrm{x}})}{\left(\overline{\mathrm{x}} \beta_{2}+\mathrm{C}_{\mathrm{x}}\right)}\left(\overline{\mathrm{X}} \beta_{2}+\mathrm{C}_{\mathrm{x}}\right) \\
\text { Kadilar and Cingi[2] }\end{array}$ & $\frac{(1-f)}{n} \frac{S_{x}^{2}}{\bar{Y}} R_{4}^{2}$ & $\frac{(1-f)}{n}\left(R_{4}^{2} S_{x}^{2}+S_{y}^{2}\left(1-\rho^{2}\right)\right)$ & $\mathrm{R}_{4}=\frac{\overline{\mathrm{Y}} \beta_{2}}{\overline{\mathrm{X}} \beta_{2}+\mathrm{C}_{\mathrm{x}}}$ \\
\hline $\begin{array}{l}\widehat{\widehat{\mathrm{Y}}}_{5}=\frac{\overline{\mathrm{y}}+\mathrm{b}(\overline{\mathrm{X}}-\overline{\mathrm{x}})}{\left(\overline{\mathrm{x}} \mathrm{C}_{\mathrm{x}}+\beta_{2}\right)}\left(\overline{\mathrm{X}} \mathrm{C}_{\mathrm{x}}+\beta_{2}\right) \\
\text { Kadilar and Cingi[2] }\end{array}$ & $\frac{(1-f)}{n} \frac{S_{x}^{2}}{\bar{Y}} R_{5}^{2}$ & $\frac{(1-f)}{n}\left(R_{5}^{2} S_{x}^{2}+S_{y}^{2}\left(1-\rho^{2}\right)\right)$ & $\mathrm{R}_{5}=\frac{\overline{\mathrm{Y}} \mathrm{C}_{\mathrm{x}}}{\overline{\mathrm{X}} \mathrm{C}_{\mathrm{x}}+\beta_{2}}$ \\
\hline $\begin{array}{l}\widehat{\mathrm{Y}}_{6}=\frac{\overline{\mathrm{y}}+\mathrm{b}(\overline{\mathrm{X}}-\overline{\mathrm{x}})}{\left(\overline{\mathrm{x}}+\beta_{1}\right)}\left(\overline{\mathrm{X}}+\beta_{1}\right) \\
\text { Yan and Tian[17] }\end{array}$ & $\frac{(1-f)}{n} \frac{S_{x}^{2}}{\bar{Y}} R_{6}^{2}$ & $\frac{(1-f)}{n}\left(R_{6}^{2} S_{x}^{2}+S_{y}^{2}\left(1-\rho^{2}\right)\right)$ & $\mathrm{R}_{6}=\frac{\overline{\mathrm{Y}}}{\overline{\mathrm{X}}+\beta_{1}}$ \\
\hline $\begin{array}{l}\widehat{\widehat{\mathrm{Y}}}_{7}=\frac{\overline{\mathrm{y}}+\mathrm{b}(\overline{\mathrm{X}}-\overline{\mathrm{x}})}{(\overline{\mathrm{x}}+\rho)}(\overline{\mathrm{X}}+\rho) \\
\text { Kadilar and Cingi[3] }\end{array}$ & $\frac{(1-f)}{n} \frac{S_{x}^{2}}{\bar{Y}} R_{7}^{2}$ & $\frac{(1-f)}{n}\left(R_{7}^{2} S_{x}^{2}+S_{y}^{2}\left(1-\rho^{2}\right)\right)$ & $R_{7}=\frac{\bar{Y}}{\bar{X}+\rho}$ \\
\hline $\begin{array}{l}\widehat{\bar{Y}}_{8}=\frac{\bar{y}+b(\bar{X}-\bar{x})}{\left(\bar{x} C_{x}+\rho\right)}\left(\bar{X} C_{x}+\rho\right) \\
\text { Kadilar and Cingi[3] }\end{array}$ & $\frac{(1-f)}{n} \frac{S_{x}^{2}}{\bar{Y}} R_{8}^{2}$ & $\frac{(1-f)}{n}\left(R_{8}^{2} S_{x}^{2}+S_{y}^{2}\left(1-\rho^{2}\right)\right)$ & $\mathrm{R}_{8}=\frac{\overline{\mathrm{Y}} \mathrm{C}_{\mathrm{x}}}{\overline{\mathrm{X}} \mathrm{C}_{\mathrm{x}}+\rho}$ \\
\hline $\begin{array}{l}\widehat{\overline{\mathrm{Y}}}_{9}=\frac{\overline{\mathrm{y}}+\mathrm{b}(\overline{\mathrm{X}}-\overline{\mathrm{x}})}{\left(\overline{\mathrm{x}} \rho+\mathrm{C}_{\mathrm{x}}\right)}\left(\overline{\mathrm{X}} \rho+\mathrm{C}_{\mathrm{x}}\right) \\
\text { Kadilar and Cingi[3] }\end{array}$ & $\frac{(1-f)}{n} \frac{S_{x}^{2}}{\bar{Y}} R_{9}^{2}$ & $\frac{(1-f)}{n}\left(R_{9}^{2} S_{x}^{2}+S_{y}^{2}\left(1-\rho^{2}\right)\right)$ & $\mathrm{R}_{9}=\frac{\overline{\mathrm{Y}} \rho}{\overline{\mathrm{X}} \rho+\mathrm{C}_{\mathrm{x}}}$ \\
\hline $\begin{array}{l}\widehat{\mathrm{Y}}_{10}=\frac{\overline{\mathrm{y}}+\mathrm{b}(\overline{\mathrm{X}}-\overline{\mathrm{x}})}{\left(\overline{\mathrm{x}} \beta_{2}+\rho\right)}\left(\overline{\mathrm{X}} \beta_{2}+\rho\right) \\
\text { Kadilar and Cingi[3] }\end{array}$ & $\frac{(1-f)}{n} \frac{S_{x}^{2}}{\bar{Y}} R_{10}^{2}$ & $\frac{(1-f)}{n}\left(R_{10}^{2} S_{x}^{2}+S_{y}^{2}\left(1-\rho^{2}\right)\right)$ & $\mathrm{R}_{10}=\frac{\overline{\mathrm{Y}} \beta_{2}}{\overline{\mathrm{X}} \beta_{2}+\rho}$ \\
\hline $\begin{array}{l}\widehat{\overline{\mathrm{Y}}}_{11}=\frac{\overline{\mathrm{y}}+\mathrm{b}(\overline{\mathrm{X}}-\overline{\mathrm{x}})}{\left(\overline{\mathrm{x}} \rho+\beta_{2}\right)}\left(\overline{\mathrm{X}} \rho+\beta_{2}\right) \\
\text { Kadilar and Cingi[3] }\end{array}$ & $\frac{(1-f)}{n} \frac{S_{x}^{2}}{\bar{Y}} R_{11}^{2}$ & $\frac{(1-f)}{n}\left(R_{11}^{2} S_{x}^{2}+S_{y}^{2}\left(1-\rho^{2}\right)\right)$ & $R_{11}=\frac{\bar{Y} \rho}{\bar{X} \rho+\beta_{2}}$ \\
\hline
\end{tabular}

\section{REFERENCES}

[1] Cochran, W. G. (1977). Sampling Techniques, Third Edition, Wiley Eastern Limited

[2] Kadilar, C. and Cingi, H. (2004). Ratio estimators in simple random sampling, Applied Mathematics and Computation
151, 893-902

[3] Kadilar, C. and Cingi, H. (2006). An Improvement in Estimating the Population mean by using the Correlation Co-efficient, Hacettepe Journal of Mathematics and Statistics Volume 35 (1), 103-109

[4] Koyuncu, N. and Kadilar, C. (2009). Efficient Estimators for the Population mean, Hacettepe Journal of Mathematics and Statistics, Volume 38(2), 217-225

[5] Murthy, M.N. (1967). Sampling theory and methods, 
Statistical Publishing Society, Calcutta, India

[6] Prasad, B. (1989). Some improved ratio type estimators of population mean and ratio in finite population sample surveys, Communications in Statistics: Theory and Methods 18, 379-392,

[7] Rao, T.J. (1991). On certain methods of improving ratio and regression estimators, Communications in Statistics: Theory and Methods 20 (10), 3325-3340

[8] Singh, D. and Chaudhary, F.S. (1986). Theory and Analysis of Sample Survey Designs, New Age International Publisher

[9] Singh, G.N. (2003). On the improvement of product method of estimation in sample surveys, Journal of the Indian Society of Agricultural Statistics 56 (3), 267-265

[10] Singh, H.P. and Tailor, R. (2003). Use of known correlation co-efficient in estimating the finite population means, Statistics in Transition 6 (4), 555-560

[11] Singh, H.P., Tailor, R., Tailor, R. and Kakran, M.S. (2004). An Improved Estimator of population mean using Power transformation, Journal of the Indian Society of Agricultural Statistics 58(2), 223-230

[12] Singh, H.P. and Tailor, R. (2005). Estimation of finite population mean with known co-efficient of variation of an auxiliary, STATISTICA, anno LXV, n.3, pp 301-313

[13] Sisodia, B. V.S. and Dwivedi, V.K. (1981). A modified ratio estimator using co-efficient of variation of auxiliary variable, Journal of the Indian Society of Agricultural Statistics 33(1), 13-18

[14] Subramani, J. and Kumarapandiyan, G. (2012). A Class of almost unbiased modified ratio estimators for population mean with known population parameters, Elixir Statistics 44, 7411-7415

[15] Subramani, J. and Kumarapandiyan, G. (2012). Modified Ratio Estimator for Population Mean Using Median of the Auxiliary Variable, Proceedings of National Conference on Recent developments in the Applications of Reliability Theory and Survival Analysis held on 2nd and 3rd February 2012 at the Department of Statistics, Pondicherry University

[16] Upadhy ay a, L.N. and Singh, H.P. (1999). Use of transformed auxiliary variable in estimating the finite population mean, Biometrical Journal 41 (5), 627-636

[17] Yan, Z. and Tian, B. (2010). Ratio Method to the Mean Estimation Using Co-efficient of Skewness of Auxiliary Variable, ICICA 2010, Part II, CCIS 106, pp. 103-110 